\title{
Correction to: Friction Reduction in Elastohydrodynamic Contacts by Thin-Layer Thermal Insulation
}

\author{
M. Björling ${ }^{1} \cdot$ W. Habchi ${ }^{2} \cdot$ S. Bair ${ }^{3} \cdot$ R. Larsson ${ }^{1} \cdot$ P. Marklund ${ }^{1}$
}

Published online: 29 August 2018

(c) Springer Science+Business Media, LLC, part of Springer Nature 2018

\section{Correction to: Tribol Lett (2014) 53:477-486 https://doi.org/10.1007/s11249-013-0286-8}

The original version of this article unfortunately contained a mistake. The correct information is given below:

The employed value for the power law exponent $\mathrm{n}$ within the shifted Carreau equation [Eq. (6)] was incorrect within the numerical codes. The real value is $n=0.463$, as reported in the paper. However, in the simulations, an incorrect value of $n=0.65$ was inadvertently employed. The below figure reproduces the friction curves of Fig. $6\left(1.25 \mathrm{GPa}, 40{ }^{\circ} \mathrm{C}\right.$ and $1.611 \mathrm{~m} / \mathrm{s}$ ). Both curves obtained using the correct and incorrect values of $\mathrm{n}$ are reported to highlight the difference among them, along with the corresponding experimental curve, for both the coated and uncoated cases.

Clearly, when the correct value of $n$ is employed, the agreement between experiments and numerical predictions is significantly improved. As such, the mistake reported in this correction does not alter any of the findings reported in the original paper. To the contrary, it further reinforces them. In addition, it highlights the importance of the role of accurate rheology in the prediction of EHL contact performance.

The original article can be found online at https://doi.org/10.1007/ s11249-013-0286-8.

M. Björling marcus.bjorling@1tu.se

1 Division of Machine Elements, Department of Engineering Science and Mathematics, Luleå University of Technology, 97187 Luleå, Sweden

2 Department of Industrial and Mechanical Engineering, Lebanese American University, Byblos, Lebanon

3 Georgia Institute of Technology, Centre for High Pressure Rheology, G.W. Woodruff School of Mechanical Engineering, Atlanta, GA 30332-0405, USA 
Fig. 6 Friction results at $1.25 \mathrm{GPa}, 40{ }^{\circ} \mathrm{C}$ at $1.611 \mathrm{~m} / \mathrm{s}$ entrainment speed comparing uncoated and coated specimens in both simulation and experiment. $n=0.463$ is the friction prediction for the updated real value
- Uncoated $n=0.65$ (Incorrect) — Uncoated $n=0.463$ (Correct) $\bigcirc$ Uncoated - Experiemental

- Co.. Coated $n=0.65$ (Incorrect) - - Coated $n=0.463$ (Correct) $\times$ Coated - Experimental

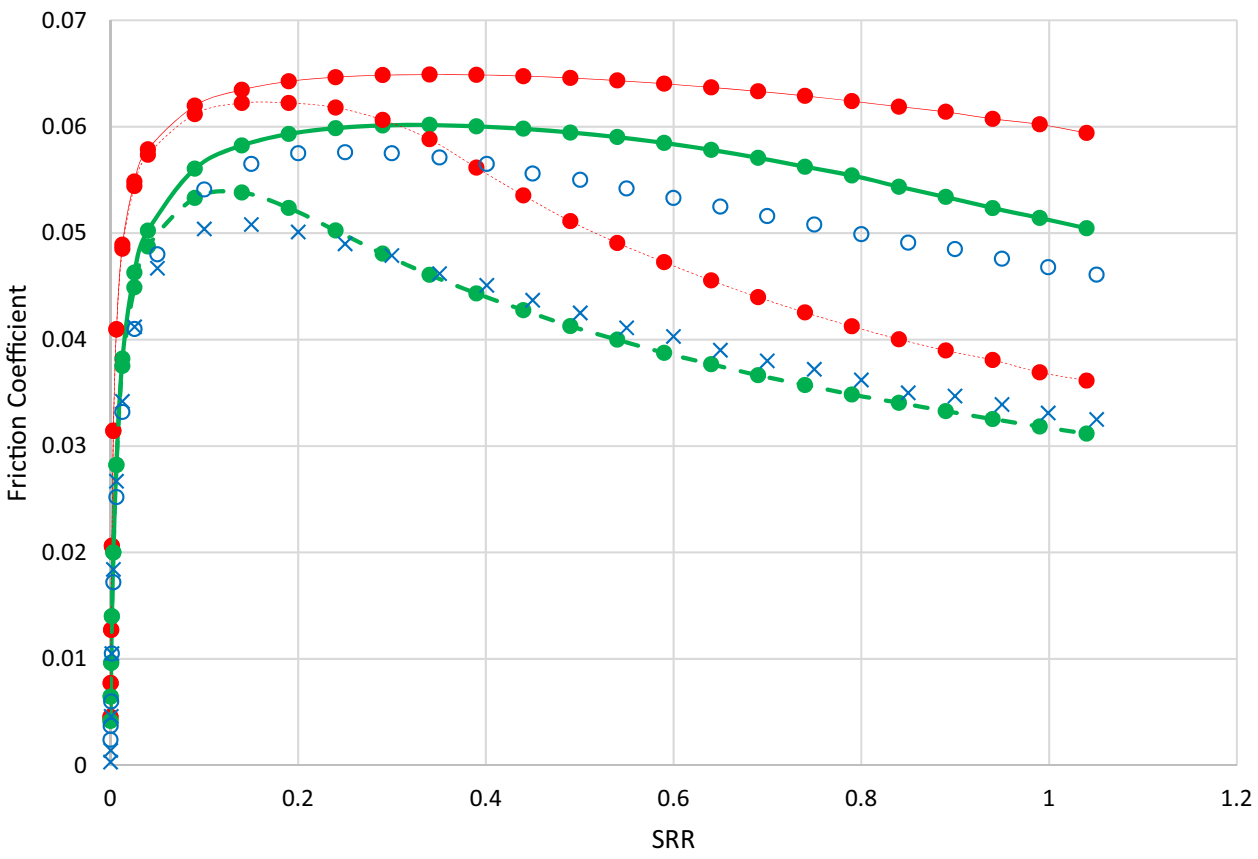

